\title{
Nuclear rDNA phylogeny in the fungal genus Verticillium and its relationship to insect and plant virulence, extracellular proteases and carbohydrases
}

\author{
Michael J. Bidochka, ${ }^{1}$ Raymond J. St Leger, ${ }^{2}$ Alison Stuart ${ }^{3}$ \\ and Karen Gowanlock ${ }^{1}$
}

Author for correspondence: Michael J. Bidochka. Tel: +1 705748 1021. Fax: +1705748 1205 . e-mail: mbidochka@trentu.ca

1 Department of Biology, Trent University, Peterborough, Ontario, Canada K9J 7B8

2 Department of Entomology, University of Maryland, College Park, MD 20742, USA

3 Department of Zoology, University of Toronto, Toronto, Ontario, Canada M5S 1 A6
Phylogenetic relationships among 18 isolates in the genus Verticillium, representing 13 species of diverse econutritional groups (pathogens of insects, plants, mushrooms, nematodes and spiders, and saprobes), were examined by using sequences from the internal transcribed spacer (ITS) and small nuclear (NS) rRNA regions. The isolates were also assessed for their abilities to infect insect larvae (Galleria mellonella) and to cause necrosis in alfalfa (Medicago sativa), and for their proteolytic, chitinolytic and pectinolytic activities. The phylogenetic data suggested that Verticillium is polyphyletic in origin and is therefore a form genus. However, the phylogenetic tree supported the plant pathogens ( $V$. dahliae, $V$. albo-atrum and $V$. nigrescens) as a clade. The alfalfa isolate of $V$. albo-atrum (isolate 595 ) was an interesting outlier to the main body of plant pathogens as it clustered with the insect pathogen $V$. indicum. Strains of $V$. lecanii and $V$. indicum were able to infect insects and are present in divergent groups in the consensus tree, suggesting that the ability to infect insects may have evolved independently many times. Similarly, the nematophagous Verticillium species appear to have evolved independently along several different routes and one isolate, $v$.

chlamydosporium, was able to infect insects. $V$. albo-atrum, $V$. nigrescens and $V$. dahliae all produced high levels of enzymes capable of degrading pectin, a major component of plant cell walls. The ability to excrete pectinase was a broad indicator of the ability to produce lesions on alfalfa. In the plant pathogens, the functions of a broad-spectrum protease were assumed by trypsins which degrade Bz-AA-AA-Arg-NA substrates (Bz, benzoyl; AA, various amino acids; NA, $p$-nitroanilide). The insect pathogens and mushroom pathogen ( $V$. fungicola) were characterized by production of high levels of subtilisin-like proteases active against a chymotrypsin substrate (succinyl-Ala $\mathbf{a}_{\mathbf{2}}$ Pro-Phe-NA) and the inability to clear pectin. The insect and mushroom pathogens, and several nematode pathogens, were distinguishable from the plant pathogens in their ability to produce chitinases.

Keywords: entomopathogenic fungi, phytopathogenic fungi, nematophagous fungi, saprophytic fungi, rDNA phylogeny 


\section{INTRODUCTION}

The genus Verticillium Nees contains a heterogeneous group of asexual fungi, many of which are of considerable importance in agriculture as pathogens of plants, insects and nematodes. The taxonomy of the group is still being reviewed and many species have a difficult and controversial characterization (Evans \& Samson, 1986; Rowe, 1995). To date, species of Verticillium have been characterized primarily on the basis of morphology and by virulence on certain hosts. The two most commercially important of the Verticillium plant pathogens, V. albo-atrum and V. dabliae, cause vascular wilts in many hosts worldwide. The wide host range with little host specificity distinguishes Verticillium fungi from many other plant pathogens. As a result, few physiological races of these plant pathogens have been found and characterized (Rowe, 1995).

Several other Verticillium species are being studied as potential biocontrol agents for insect and nematode pests. These Verticillium spp. have a wide host range with little host specificity. Thus, the insect pathogen $V$. lecanii and the nematode pathogen $V$. chlamydosporium are hyperparasites on other fungi (Leinhos \& Buchenauer, 1992). The pathogens of fungi, V. fungicola and $V$. lamellicola, are also pathogenic to mites and insects (Balazy et al., 1987). In addition, morphological differences between Verticillium species are minor, with virtually no differences in conidial morphology. Nevertheless, in a recent study, strains of V. albo-atrum and $V$. lecanii were found to show enzymic adaptation to the polymers present in the integuments of their plant and insect hosts respectively, implying pathogenic specialization to the requirements of these ecological niches $(\mathrm{St}$ Leger et al., 1997). This suggests that Verticillium spp. could be a useful model in the study of the evolution of pathogenic mechanisms.

Several current problems in our understanding of Verticillium fungi have resulted from the inability to recognize the phylogenetic relationships within this group (Jun et al., 1991). Because of this uncertainty, and because we are interested in understanding the genetic basis for the evolution of pathogenicity, it is important to develop a molecular phylogeny of this group that is independent of morphology. Previous biochemical and molecular studies have focused almost exclusively on the two major plant pathogens $V$. albo-atrum and $V$. dabliae. Methods used for diagnosis of these species include vegetative incompatibility analysis (Joaquim \& Rowe, 1990), random amplification of polymorphic DNA (RAPD; Barasubiye et al., 1995), and restriction fragment length polymorphisms (RFLP; Okoli et al., 1993, 1994; Typas et al., 1992).

Recently, the genetic diversity in V. dabliae and V. alboatrum was evaluated using PCR technology and exploiting variations in rRNA or mitochondrial rRNA genes (Griffen et al., 1997). Li et al. (1994) used a pair of conserved PCR primers to amplify a region of the mitochondrial small rRNA gene. Employing this fragment in an RFLP analysis differentiated 10 species of
Verticillium and allowed development of a V. dabliaespecific primer. Robb et al. (1993) utilized the nucleotide variability in the internal transcribed spacer (ITS) regions of nuclear rRNA to develop specific PCR-based assays. The ITS regions between $18 \mathrm{~S}$ and $28 \mathrm{~S}$ rDNA were amplified from V.albo-atrum, V. tricorpus and V. dabliae, cloned and then sequenced. Primers were then synthesized based on specific nucleotide differences found in the ITS regions that were characteristic of each species (Hu et al., 1993; Moukhamedov et al., 1994; Nazar et al., 1991; Robb et al., 1993). A similar technique has been applied to resolve the genetic variation between isolates of $V$. chlamydosporium using restriction fragment analysis of PCR-amplified ITS and the intergenic spacers (IGS) that separate ribosomal repeat units (Arora et al., 1996). These studies were mostly focused on providing a tool for unambiguous identification and enumeration of individual Verticillium species. It seems evident that rDNA is sufficiently variable to provide characters for phylogenetic analysis of this diverse genus. In particular, because it contains interspersions of variable and more highly conserved regions that represent differing rates of evolution, $\mathrm{rDNA}$ may allow differentiation and detection at a wide range of specificities.

In the present study we used the ITS1 (internal transcribed spacer) region and a portion of the relatively more conserved small nuclear (NS) region of rDNA to provide phylogenetic information for a fairly broad range of Verticillium species. In contrast to the previous studies on Verticillium we chose to analyse rDNA sequences as this strategy provides much more phylogenetic information than comparing RFLP banding patterns of the amplified regions of rDNA. We also investigated the relationship of phylogeny with the production of hydrolytic enzymes (putative pathogenicity/virulence determinants) and pathogenicity against a plant (alfalfa) and insect (waxworm larvae) species, with the aim of gaining insight into the evolution of Verticillium pathogenicity, and facilitating the design and implementation of more effective screening programmes for biocontrol agents.

\section{METHODS}

Fungal strains, cultivation and DNA extraction. The Verticillium isolates used in the analysis are listed in Table 1 . Cultures were maintained on $1.5 \%(\mathrm{w} / \mathrm{v})$ agar containing $0.2 \%$ yeast extract, $1 \%$ peptone, $2 \%$ glucose (YPD) at $22{ }^{\circ} \mathrm{C}$. In liquid cultures, $50 \mathrm{ml}$ YPDY $[0 \cdot 1 \%(\mathrm{w} / \mathrm{v})$ yeast extract, $1 \%$ peptone, $2 \%$ glucose, $0 \cdot 1 \%$ yeast nitrogen base] was inoculated with conidia taken from 7-14-d-old agar plates. The $250 \mathrm{ml}$ Erlenmeyer flasks were incubated with shaking (100 r.p.m.) at $22{ }^{\circ} \mathrm{C}$ for up to $7 \mathrm{~d}$ and then aseptically collected on Whatman no. 1 filter paper under vacuum filtration and stored at $-70{ }^{\circ} \mathrm{C}$.

Genomic DNA was extracted by grinding the mycelium into a fine powder with a mortar and pestle (approx. $5 \mathrm{~min}$ ) under liquid nitrogen. A sample of the powder was transferred to a tube containing $4 \mathrm{ml}$ lysis buffer $(0 \cdot 1 \mathrm{M}$ Tris, $0 \cdot 1 \mathrm{M}$ EDTA, $2 \%$ SDS, pH 8.0 with $\mathrm{NaOH}$ ) and incubated at $65^{\circ} \mathrm{C}$ for $1 \mathrm{~h}$. The mixture was centrifuged at 7000 r.p.m. for $10 \mathrm{~min}$ and the 
Table 1. Species, strains and origins of fungi used in this study

\begin{tabular}{|c|c|c|c|c|}
\hline Species & $\begin{array}{c}\text { Strain } \\
\text { no. }\end{array}$ & Isolation/host & $\begin{array}{c}\text { Geographical } \\
\text { origin }\end{array}$ & Source" \\
\hline V. albo-atrum Reinke \& Berthold & 5393 & Alfalfa & Canada & UAMH \\
\hline V. albo-atrum & 595 & Contaminant & Canada & $\mathrm{UAMH}$ \\
\hline V. nr. aranearum (Petch) Gams & 1905 & Spider & Solomon Isl. & ARSEF \\
\hline V. coccosporum (Dreschsler) Gams & 2064 & Lymantria dispar (Lepidoptera) & USA & ARSEF \\
\hline V. coccosporum & 6596 & Decaying mushroom & Canada & UAMH \\
\hline V. dahliae Klebahn & 5360 & Eggplant & Canada & UAMH \\
\hline V. fungicola (Preuss) Hassebr. & 895 & Mushroom pathogen & Canada & $\mathrm{UAMH}$ \\
\hline V. lecanii (Zimmerman) Viegas & 991 & Bombyx mori (Lepidoptera) & Japan & ARSEF \\
\hline V. lecanii & 7184 & Rover beetle & Canada & UAMH \\
\hline V. leptobactrum Gams & 5951 & Mycorrhizal associate & Canada & UAMH \\
\hline V. nigrescens Pethybr. & 6687 & Soil(?) & Canada & UAMH \\
\hline V. rexianum (Sacc.) Sacc. & 1691 & Wood saprophyte & Canada & $\mathrm{UAMH}$ \\
\hline
\end{tabular}

*UAMH, University of Alberta Microfungus Collection and Herbarium; ARSEF, USDA Entomopathogenic Fungus Collection at Cornell University.

supernatant extracted twice with an equal volume of phenol/ chloroform/isoamyl alcohol ( $25: 24: 1$, by vol.). Nucleic acids were precipitated with the addition of $0 \cdot 1$ vol. $3 \mathrm{M}$ sodium acetate and $0.8 \mathrm{vol}$. 2-propanol. The nucleic acids were centrifuged and washed with $70 \%$ ethanol, air-dried and resuspended in distilled deionized water. RNA was digested by the addition of $25 \mathrm{ng}$ RNase A (Boehringer Mannheim) per $100 \mu \mathrm{l} \mathrm{DNA}$ solution and incubation at $37^{\circ} \mathrm{C}$ for $2 \mathrm{~h}$. DNA integrity and concentration of the samples was determined by comparison with markers of known concentration by electrophoresis on $0 \cdot 8 \%$ agarose gels.

DNA amplification and sequencing. A region of the NS rRNA gene and a portion of the ITS1 region were amplified using the primer pairs NS7 and NS8, and ITS1 and ITS2, respectively, and an MJ Research Minicycler with protocols outlined by White et al. (1990). The PCR products were analysed by electrophoresis on $0.8 \%$ agarose gels. After determining that the PCR products each contained one band, they were purified (QIAquick PCR purification kit, Qiagen) using methods outlined in the protocol. Sequencing was performed at the Queen's University Biochemistry DNA sequencing facility (Kingston, ON) with the same primers as used for PCR.

Sequence analysis and phylogenetics. Two sequences of rDNA each were obtained for 18 taxa of Verticillium. The region of the NS rDNA sequence, a conserved region, was approximately $350 \mathrm{bp}$ in length for all taxa. The ITS1 region, a relatively non-conserved region, was approximately $650 \mathrm{bp}$ in length for all taxa. Constructing phylogenies using molecular data requires five basic steps. Initially the sequences must be aligned, the informative characters tested for phylogenetic signal, the data analysed, a tree selected and, finally, nodal support evaluated (Hillis et al., 1993). The two sets of data were first analysed separately. The sequences were pre- aligned using SeqEd (Applied Biosystems, 1992) and handled independently throughout the following procedures. The sequences were transferred from SeqEd to ESEE3 (Cabot \& Beckenbach, 1989), a program that allows visual alignment. The ITS1 region contained many gaps and insertions, making realignment necessary. The NS rDNA region had only one base-pair gap and the alignments with both methods were identical. Any unalignable regions were removed from the analysis because positional homology cannot be assured (Swofford \& Olsen, 1990). The sequences were transferred into a MacClade (Maddison \& Maddison, 1992) readable format. Any uninformative characters (simple isomorphs) were then deleted, leaving 45 characters for the ITS1 regions and 78 NS rDNA characters. To determine if phylogenetic signal was apparent, the matrices were transferred to PAUP (Swofford, 1991) and the random trees option selected. One thousand random trees were generated and the G1 statistics produced. This value was compared against a G1 table to determine significance (Hillis \& Huelsenbeck, 1992). PTP values were determined by transferring the matrices to a Hennig86 (Farris, 1988) format and running PTP analysis in random cladistics (Siddell, 1996). One hundred replicates were assessed.

The MacClade matrices were transferred to PAUP in order to determine the most parsimonious resolutions of the data. Aspergillus niger was designated as the outgroup, and branch and bound searches were performed. All characters were run unordered and initially equally weighted. If the outcome revealed multiple equally parsimonious trees (MEPTs) then the characters were reweighted based on the rescaled consistency index and the search repeated. This process was repeated until the number of MEPTs could no longer be reduced. Consistency and retention indices were noted. If there were still MEPTs, strict, semi-strict, $50 \%$ majority rule 
and Adams consensus trees were analysed. One of the MEPTs was then chosen that matched either the semi-strict or $50 \%$ majority rule tree and was used for the analysis.

Nodes on most resulting phylogenies had bootstrap values and the number of characters defining that node. The bootstrap values were obtained by transferring the data to a Hennig86 file (Farris, 1988) and running the Heyjoe program in random cladistics. One hundred replicates were performed and the values placed at the appropriate node on the phylogeny produced above.

The characters were assessed in MacClade using the trace character tool. Each character was assessed for appearance on the phylogeny and whether it was an unreversed or homoplastic character. Total number of characters and number of unreversed characters were placed on each node of the phylogeny.

The above procedure was repeated for the ITS region and NS rDNA sequences with the transversion : transition ratio changed from $1: 1$ to $5: 1$. This weighs transversions (i.e. purine to pyrimidine) five times greater than transitions. PTP and bootstrap values were not calculated because the Hennig86 cannot compute ratios different from $1: 1$. The resulting topologies were compared with the $1: 1$ ratio phylogenies produced above. The consistency index (CI) and retention index $(\mathrm{RI})$ values were not calculated for these phylogenies. Total number of characters and the number of transversed characters are noted at each node.

The 78 rDNA and 45 ITS characters were combined into one matrix in MacClade and the entire analysis repeated. Thus, two combined phylogenies were produced, one unordered and the other with a transversion:transition ratio of $5: 1$. Nodal support values were identical to those previously determined.

Insect virulence. Wax moth larvae (Galleria mellonella) were allowed to crawl over sporulating cultures of each strain of Verticillium (eight larvae per strain) for $15 \mathrm{~min}$. They were then placed individually into $100 \mathrm{~mm}$ Petri dishes containing a moistened filter paper. After $1 \mathrm{~d}$, larvae were provided with artificial diet (Carolina Biological Supplies) and monitored daily for $14 \mathrm{~d}$. If larvae died, cadavers were placed on water agar for $3 \mathrm{~d}$ to detect potential production of hyphae and conidia. If no external evidence of fungal growth was detected, cadavers were dissected and samples examined microscopically to document hyphal bodies in the haemocoel and fat body.

Plant virulence. We adopted a laboratory method based on artificial infection of detached leaves as this has been found to be an efficient method of evaluating resistance of alfalfa plants to $V$. albo-atrum (Huang, 1989). Stem cuttings were excised from 7-week-old alfalfa plants (Medicago sativa, var. Iroquois) and surface disinfected ( $0.25 \%$ sodium hypochlorite, $5 \mathrm{~min}$, and four changes of sterile distilled water). The cuttings were placed on $1 \%$ water agarose and (usually) two out of three leaflets near the top of each cutting were point-inoculated with spores of each strain by pricking the middle vein of leaflets with a needle previously dipped into a sporulating culture of the test fungus. In preliminary experiments, we found that wounding the leaf was required for chlorosis to occur, as distinct from growth over the leaf surface. An alternative method of inoculation, injecting known quantities of spores into the middle vein with a hypodermic syringe, did not change results compared with the less precise method of using a needle. All the cuttings were incubated in a growth cabinet at $20^{\circ} \mathrm{C}$ with a $16 \mathrm{~h}$ day. One week after inoculation, leaves were evaluated and the zone of necrosis was measured.

Plate clearing assays for chitinase and pectinase. Chitinase activity was detected using minimal medium supplemented with $0.05 \%$ yeast extract and $0.2 \%$ (dry weight) colloidal chitin adjusted to $\mathrm{pH} 5 \cdot 5$. Plates were prepared as described by Hankin \& Anagnostakis (1975) with an underlay of $1.5 \%$ agar and a $3 \mathrm{~mm}$ overlay of the chitin medium. Pectinase activity was detected using minimal medium supplemented with polymethylgalacturonan (pectin) buffered at $\mathrm{pH} 8.0(0.05 \mathrm{M}$ HEPES) and containing calcium-rich agar (Durrands \& Cooper, 1988). Pectinase activity was detected on this medium by addition of $1 \%(\mathrm{w} / \mathrm{v})$ cetyltrimethylammonium bromide, which precipitated undegraded substrate.

Protease assays. Conidia $\left(2 \times 10^{6}\right)$ were inoculated into $15 \mathrm{ml}$ cuticle/basal salts medium (St Leger et al., 1997) and incubated with shaking (100 r.p.m.) at $23^{\circ} \mathrm{C}$ for 3 d. Protease production was evaluated by assaying culture filtrates (Whatman no. 1 filter paper) against a range of substrates previously used to detect subtilisins and trypsins in insect and plant pathogens $(\mathrm{St}$ Leger et al., 1987, 1997).

\section{RESULTS}

\section{rDNA phylogenetic analysis of Verticillium species}

Fig. 1 is one of the MEPTs and also the $50 \%$ majority rule tree. The total tree length was 1273 characters (when all characters were reweighted by 10 ). All data matrices were shown to contain phylogenetic signal from both the G1 statistic and PTP methods $(P<0 \cdot 01)$. The combined data set included 123 informative characters. Six MEPTs were produced after successively weighting the characters. The isolates within the $V$. lamellicola, V. lecanii and V. coccosporum species were each resolved as sister taxa in this phylogeny. The two $V$. albo-atrum isolates could be made monophyletic but only with an addition of $26.5 \%$ total tree length. The two $V$. fungicola isolates required an additional $13.5 \%$ of the tree length to result in monophyly.

Fig. 2 is one of 12 MEPTs for 20 isolates as well as the strict consensus tree when the combined data set was analysed with a transition:transversion of $5: 1$. The total tree length was 6070 characters (when all characters were reweighted by 10). There are some differences between this tree and the unordered tree (Fig. 1). $V$. fungicola 895 is resolved as the sister to V. chlamydosporium. Contrary to most of the unordered MEPTs, the $V$. dabliae, $V$. albo-atrum 5393 and $V$. nigrescens clade now resolved as the sister group to the clade including $V$. aranearum on all 12 MEPTs. When the unordered tree (Fig. 1) is altered to the transversion::transition topology only one additional step is required $(0.4 \%$ difference), indicating that areas of the unordered phylogeny were unstable. As in Fig. 1, the isolates within the $V$. lamellicola, $V$. lecanii and $V$. coccosporum species were each resolved as sister taxa in this phylogeny. However, to make the V. albo-atrum isolates monophyletic required a $19.4 \%$ change in tree length, and to produce monophyly in the V. fungicola isolates required a $12.5 \%$ tree length change. 

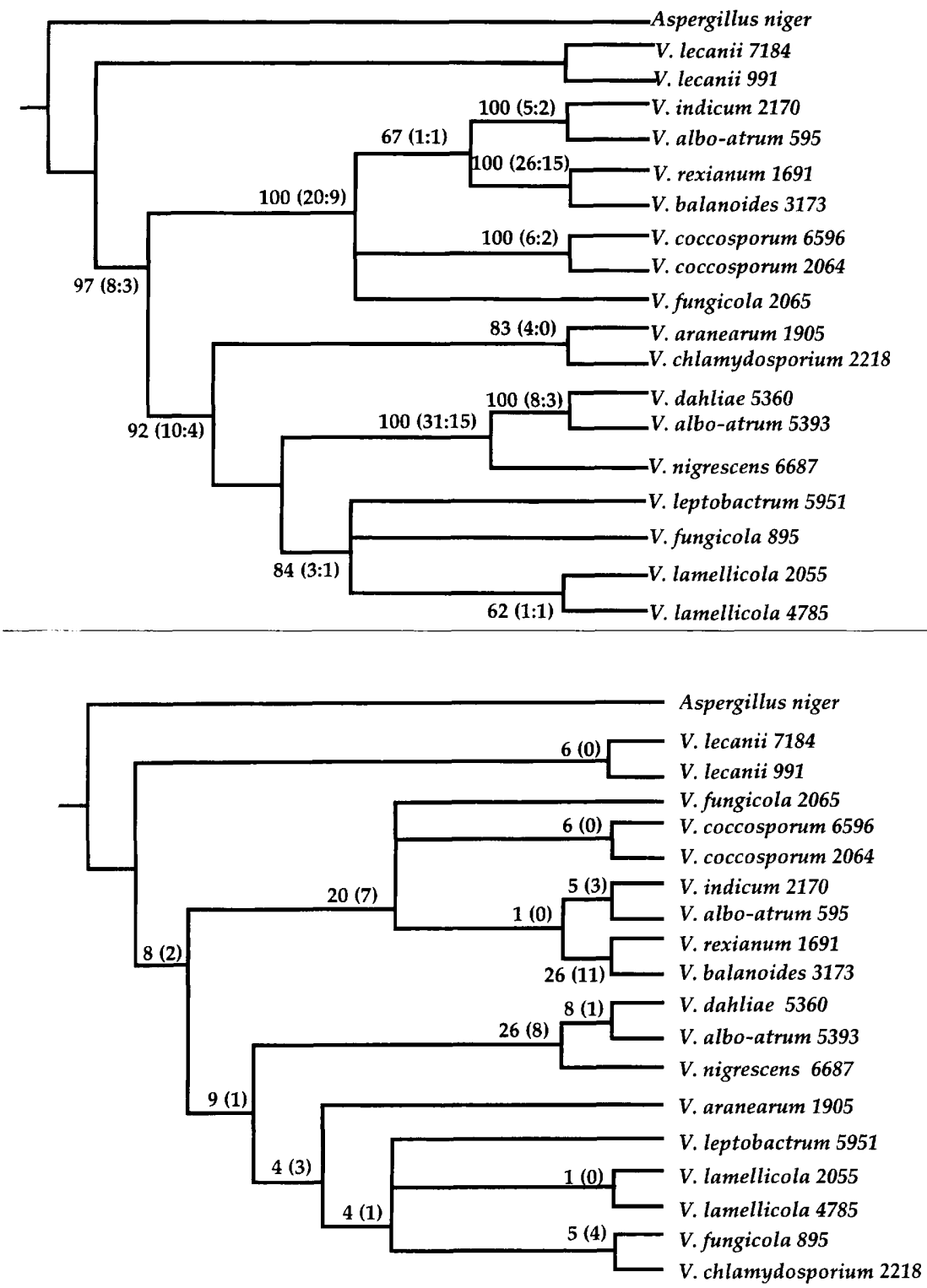

Fig. 1. One of the six MEPTs, the $50 \%$ majority rule, produced from all informative characters (ITS plus a region of the NS rDNA) for 19 taxa of fungi. Values given at each node represent the bootstrap value (ratio of total number of characters:number of unreversed characters).

\section{Enzymic diversity of Verticillium spp.}

Extracellular protease activity on four substrates was determined in Verticillium isolates (Table 2). Isolates of the insect pathogens, V. lecanii and $V$. indicum, and the mushroom pathogen, $V$. fungicola, cleaved the subtilisin substrate Suc-Ala-Ala-Pro-Phe-NA faster than Bz-PheVal-Arg-NA, and except for $V$. indicum, possessed little or no activity against Bz-Val-Gly-Arg-NA or Bz-ProPhe-Arg-NA, indicating that the trypsins of these species require a specific substrate sequence (Phe-Val-Arg). The nematode pathogens, $V$. coccosporum, V. lamellicola and $V$. chlamydosporium, and the spider pathogen, $V$. $n r$. aranearum, were distinguishable from the insect pathogens by producing lower levels of subtilisin-like proteases as compared to the trypsin activity, although these had the same narrow specificity as the enzymes from the insect pathogens. In contrast the plant pathogens ( $V$. albo-atrum, $V$. dabliae and $V$. nigrescens) hydrolysed all three trypsin substrates and cleaved the most susceptible of these (Bz-Val-Gly-Arg-NA) at least twofold faster than the subtilisin substrate, Suc-Ala-AlaPro-Phe-NA.

Chitinase and pectinase production by Verticillium strains is shown in Table 3 . Chitinase production by strains of Verticillium species determined in plate clearing assays correlated with the ability to produce high levels of subtilisins and narrow-spectrum trypsins in liquid culture. Thus, $V$. fungicola, a mushroom pathogen, and the insect and nematode pathogens produced clearing zones in chitin medium while the plant pathogens did not, indicating that if chitinases are secreted by this group they were at a level below the sensitivity of the assay. By contrast, V. coccosporum and $V$. chlamydosporium, and the plant pathogens, were all able to degrade pectin (Table 3). Isolates of the insect pathogens and $V$. fungicola did not produce detectable levels of pectinase. 
Table 2. Extracellular protease activity and substrate specificity of the Verticillium species

Protease activity was measured spectrophotometrically in culture filtrates after $3 \mathrm{~d}$ growth in $1 \%$ cuticle/basal salts medium. Results in columns A-E represent mean percentage protease activities for each species. Substrates: A, Suc-(Ala) ${ }_{2}$-Pro-Phe-NA; B, Bz-Phe-Val-Arg-NA; C, Bz-Val-Gly-ArgNA; D, Bz-Pro-Phe-Arg-NA. Results in column $E$ are the absolute values in nmol NA released $\min ^{-1} \mathrm{ml}^{-1}$ corresponding to $100 \%$ activity (St Leger et al., 1987, 1997).

\begin{tabular}{|c|c|c|c|c|c|}
\hline \multirow[t]{2}{*}{ Verticillium species* } & \multicolumn{4}{|c|}{$\begin{array}{c}\text { Percentage of rnaximum protease } \\
\text { activity by substrate: }\end{array}$} & \multirow[b]{2}{*}{$\mathbf{E}$} \\
\hline & A & B & $\mathrm{C}$ & $\mathrm{D}$ & \\
\hline V. albo-atrum 595 & 28 & 39 & 100 & 14 & (212) \\
\hline V. albo-atrum 5393 & 26 & 58 & 100 & 28 & (197) \\
\hline V. nr. aranearum 1905 & 7 & 100 & 7 & 7 & (147) \\
\hline V. chlamydosporium 2218 & 24 & 100 & 12 & 11 & (83) \\
\hline V. coccosporum 2064 & 7 & 100 & 6 & 5 & (219) \\
\hline V. coccosporum 6596 & 38 & 100 & 18 & 18 & (238) \\
\hline V. dabliae 5360 & 35 & 42 & 100 & 34 & (231) \\
\hline V. fungicola 895 & 100 & 29 & 0 & 0 & $(80)$ \\
\hline V. fungicola 2065 & 100 & 68 & 0 & 0 & (138) \\
\hline V. indicum 2170 & 100 & 38 & 14 & 12 & (102) \\
\hline V. lamellicola 2055 & 62 & 100 & 24 & 6 & (44) \\
\hline V. lamellicola 4785 & 65 & 100 & 29 & 8 & (53) \\
\hline V. lecanii 991 & 100 & 74 & 2 & 0 & (214) \\
\hline V. lecanii 7184 & 100 & 53 & 3 & 1 & (87) \\
\hline V. nigrescens 6687 & 53 & 86 & 100 & 32 & (86) \\
\hline
\end{tabular}

$*$ V. balanoides 3173, V. leptobactrum 5951 and $V$. rexianum 1691 grew poorly in $1 \%$ cuticle/basal salts medium.

Table 3. Pectinase and chitinase activities of the Verticillium species and virulence against wax moth larvae and alfalfa

Enzyme activities were calculated as an index of the total diameter of the colony plus the clear zone around it divided by the diameter of the colony. A value $>1.0$ indicates that the isolate is releasing the enzyme into the surrounding medium. Virulence against waxworm larvae is shown as $\mathrm{LT}_{50}$ in $\mathrm{d}$; virulence against alfalfa is shown as the diameter of the zone of necrosis, in $\mathrm{mm}$, after $7 \mathrm{~d}$. All values are means of five measurements. Blank spaces indicate no clearing on pectin or chitin agar plates, $\mathrm{LT}_{50}$ values not lower than the control mortality, or no zone of necrosis.

\begin{tabular}{|c|c|c|c|c|}
\hline \multirow[t]{2}{*}{ Verticillium species* } & \multicolumn{2}{|c|}{ Enzyme assays } & \multicolumn{2}{|c|}{ Bioassays } \\
\hline & Pectinase & Chirinase & Insect & Alfalfa \\
\hline V. albo-atrum 595 & $3 \cdot 21$ & & & $2 \cdot 00$ \\
\hline V. albo-atrum 5395 & $2 \cdot 93$ & & & 3.00 \\
\hline V. chlamydosporium 2218 & $2 \cdot 10$ & 1.01 & $5 \cdot 00$ & \\
\hline V. coccosporum 2064 & 3.09 & 1.09 & & \\
\hline V. coccosporum 6596 & $2 \cdot 73$ & $1 \cdot 08$ & & \\
\hline V. dabliae 5360 & $2 \cdot 74$ & & & $3 \cdot 38$ \\
\hline V. fungicola 895 & & $1 \cdot 21$ & & \\
\hline V. fungicola 2065 & & $1 \cdot 25$ & & \\
\hline V. indicum 2170 & & $1 \cdot 15$ & $2 \cdot 56$ & \\
\hline V. lecanii 991 & & $1 \cdot 37$ & $3 \cdot 62$ & \\
\hline V. lecanii 7184 & & $1 \cdot 10$ & $4 \cdot 87$ & \\
\hline V. nigrescens 6687 & $2 \cdot 89$ & & & $1 \cdot 25$ \\
\hline
\end{tabular}

* No detectable pectinase or chitinase activities, or trace alfalfa necrosis and no insect virulence, was observed from V. nr. aranearum 1905, V. rexianum 1691 , V. balanoides 3173 , V. lamellicola 2055 and 4785. 


\section{Pathogenicity profiles}

Variations in pathogenicity and host range among the isolates of Verticillium species were determined against an insect (the wax moth, Galleria mellonella) and a strain of alfalfa susceptible to wilt disease (Table 3). Pathogenicity against insects was evaluated by externally inoculating larvae with conidia. Mortality values were very low for non-inoculated controls $(<5 \%)$. Consequently mortality among treated larvae was almost always due to fungal infection. Of the 18 Verticillium isolates tested, four caused mortality and all of these successfully produced hyphae and spores on the cadaver. $V$. indicum was particularly virulent, killing all the test insects within $3 \mathrm{~d}$ of inoculation, and then rapidly covering the cadavers in a thick pelt of hyphae. Isolates of $V$. lecanii were also pathogenic, as was an isolate of V. chlamydosporium (2218). Insects exposed to other isolates remained symptomless and showed mortality values less than or equal to the non-inoculated controls.

The alfalfa leaves needed to be wounded to allow infection and necrosis of plant tissues. This was expected, as plant-pathogenic Verticillium species normally infect via the roots, where wounds may considerably increase the amount of infection (Evans \& Gleeson, 1973). Leaves infected with the known plantpathogenic species ( $V$. albo-atrum, $V$. dabliae and $V$. nigrescens) displayed chlorosis after injection of the fungal inoculum (Table 3). Leaflets infected with most of the nematode pathogens, V. indicum and V. fungicola remained symptomless.

\section{DISCUSSION}

Based primarily on morphological criteria, the genus Verticillium is divided into four sections and a residual group (Gams, 1988; Gams \& Van Zaayen, 1982). The section Nigrescentia comprises the plant pathogens and some saprophytic species with dark resting structures. This feature appears to reflect underlying phylogenetic relatedness, as V. albo-atrum (5393), V. dabliae and $V$. nigrescens were monophyletic in the phylogenetic trees produced (Figs 1 and 2). The section Prostrata contains the soil-dwelling and nematophagous species ( $V$. chlamydosporium, V. balanoides, V. lamellicola, V. leptobactrum and $V$. coccosporum) as well as other species such as $V$. fungicola and $V$. lecanii with conidiophores at least partly prostrate. These species are polyphyletic, implying that the section Prostrata does not reflect evolutionary history. In fact, $V$. balanoides is the sister taxon of $V$. rexianum, a fungicolous species classified in the section Albo-erecta, with erect conidiophores (Gams \& Van Zaayen, 1982). This suggests that the conidiophore-erect criterion, a key morphological characteristic for distinguishing among Verticillium species (Gams, 1988), is not a useful indicator of phylogenetic relatedness.

In spite of their phylogenetic divergence, the entomopathogens $V$. lecanii and $V$. indicum were all characterized by the production of high levels of subtilisin-like proteases, suggesting that this may be a broadly predictive indicator of entomopathogenicity. However, subtilisin-like proteases also constituted the major protease component secreted by the mushroom pathogen $V$. fungicola. Broad-spectrum subtilisins are the major proteins produced by the insect pathogens Metarhizium anisopliae and Beauveria bassiana during infection processes, and have much greater ability than the trypsin-like enzymes to degrade insect cuticle (St Leger \& Bidochka, 1996). It would be interesting to determine whether subtilisin-like proteases are also involved in degrading certain mushroom tissues. The question arises as to whether the predominance of subtilisins is a derived condition reflecting adaptation to entomopathogenicity, or is retained from a saprophytic ancestor. The latter may be the case since subtilisin-related proteases are the principal broad-spectrum proteases produced by many saprophytes (Gunkle \& Gassen, 1989), so they are unlikely to represent the tools specifically developed by entomopathogenic fungi to implement pathogenicity. Also, the basal position of the subtilisin-producing entomopathogen $V$. lecanii at the convergence point of the consensus tree suggests that it is closest to the lineage that gave rise to the other Verticillium spp. Although $V$. indicum, $V$. chlamydosporium and $V$. lecanii do not form a monophyletic group, none of the insect or nematode pathogens produced pectinase, indicating independent adaptation by both lineages to an ecological niche where pectinase is not required.

In contrast to the invertebrate pathogens, the plant pathogens V. albo-atrum (isolate 5393), V. dabliae and $V$. nigrescens are monophyletic in all MEPTs regardless of weight or sequences used. They also exhibited the most evident correlation (as compared to insect and nematode pathogens) between genetic similarity, enzyme production and pathogenicity. Apparently, during adaptation of these Verticillium spp. to the plant cell wall the functions of a broad-spectrum protease were assumed by trypsins. As there are no reports of trypsins being produced by saprophytes, trypsin-related enzymes might have a specific role in pathogenicity. The plant pathogen Cochliobolus carbonum also produces a broad-spectrum trypsin, which may be involved in degrading hydroxyproline-rich proteins in plant cell walls (Murphy \& Walton, 1996). As befits their status as plant pathogens, V. albo-atrum, V. nigrescens and $V$. dabliae all produced high levels of enzymes capable of degrading pectin, one of the principal components of plant cell walls.

Two separate studies, one employing RFLP (Carder \& Barbara, 1991) and the other RAPD analysis (Barasubiye et al., 1995), demonstrated that isolates of V.albo-atrum pathogenic to alfalfa were clearly differentiated from other $V$. albo-atrum isolates and warranted a separate taxonomic status. The alfalfa isolate of $V$. albo-atrum (isolate 595) thus provided an interesting outlier to the main body of plant pathogens as the sister taxon to the insect pathogen $V$. indicum. Isolate 595 was clearly more closely related phylogenetically than physiologically to $V$. indicum as it was very similar to $V$. albo- 
atrum 5393 in enzyme production. Similarly, V. fungicola 895 resolved in a monophyletic group that included $V$. lamellicola isolates while V. fungicola 2065 resolved in a monophyletic group that included V. coccosporum isolates; this suggests that a separate taxonomic status may also apply to some $V$. fungicola isolates. However, the $V$. fungicola isolates were also physiologically similar to each other in their protease, pectinase and chitinase profiles. Whereas neither of the $V$. fungicola isolates was pathogenic to G. mellonella larvae, strain 2065 was isolated from gypsy moth larvae (Lymantria dispar), while strain 895 was isolated from a mushroom. These results indicated that similar enzyme production and pathogenicity does not always translate into phylogenetic relatedness, and vice versa.

Several investigations have identified genetic variability in some Verticillium spp. and have attempted to correlate this to virulence. Okoli et al. (1994) utilized RFLP to differentiate isolates of $V$. dabliae with differing pathogenicities on several plant species. $V$. fungicola isolates were differentiated by RAPD analysis, and limited correlations with fungicide response and geographic origin were found, but not with virulence toward mushroom or colony morphology (Bonnen \& Hopkins, 1997). Beyond this there is little information on the relatedness between genotype diversity and pathogenicity to different host groups, e.g. insects, plants, nematodes or mushrooms. Determining the differences between closely related plant and insect pathogens will indicate probable key virulence characters for pathogenicity of the two host groups and may help determine how pathogenicity evolved. The phylogenetic analysis suggested that the common ancestor was an insect pathogen, and that plant pathogenicity evolved secondarily. This is evident by moving more basally on the phylogeny and noting the state of the most recent ancestors.

The nematophagous Verticillium species can be grouped ecologically into species that become attached to the surface of free-living nematodes, whence they penetrate the host (e.g. V. balanoides and V. coccosporum), and the species that infect nematode cysts and eggs (e.g. $V$. lamellicola, V. leptobactrum and V. chlamydosporium) (Gams, 1988). Evidently, as with the insect pathogens, nematophagous Verticillium species have evolved independently several times to achieve their success as pathogens. Nevertheless, a phylogenetic branch is shared by the nematode pathogens that prefer to penetrate the host and this is distinctive from a common branch by the isolates that infect nematode cysts and eggs. This suggests that the patho-ecological groupings may correlate with two different lineages. Verticillium species are known to have a broad host range with little host specificity (Rowe, 1995), and some of the isolates of nematophagous species we studied here were originally obtained from insect hosts. The genetic and biochemical versatility this implies may (1) reflect maintenance of the ability to exploit resources that temporarily become available, and (2) indicate that some of the underlying mechanisms of fungal pathogenesis may be similar in insects and nematodes. Both the nematophagous and the entomophagous Verticillium species produce an ordered sequence of infection structures including appressoria, and V. chlamydosporium resembles insect pathogens in secreting subtilisins to breach the hosts' proteinaceous cuticles (Segers et al., 1994). However, the major protease components secreted by the nematode pathogens were trypsins with a narrow specificity toward PheVal-Arg. Besides proteins, the outer integuments of insects, nematodes and mushrooms contain chitin as a major structural component. Consistent with adaptation of enzyme production to the specific needs of different Verticillium spp. on their particular hosts, the insect, nematode and mushroom pathogens are distinguishable from the plant pathogens by their ability to produce chitinases.

The ability to infect nematodes may pre-adapt Verticillium species to infect insects also. However, the converse is unlikely to be true as, in spite of its abundance, $V$. lecanii very rarely attacks nematodes (Gams, 1988). V. chlamydosporium is most commonly regarded as a saprophytic soil fungus and, though a potent pathogen of nematode eggs, may be the least dependent on nematodes for its development (Gams, 1988). Unlike the insect and plant pathogens, the nematode pathogens $V$. chlamydosporium and V. coccosporum produced pectinases and chitinases. This broad spectrum of polysaccharide-hydrolysing enzymes may be indicative of a less specialized nutritional status than that shown by the plant and insect pathogens, consistent with the ability to grow on a greater variety of living and non-living organic substrates.

\section{ACKNOWLEDGEMENTS}

M.J.B. expresses thanks to the Natural Sciences and Engineering Research Council of Canada for financial assistance in the form of an operating grant. A.E.S. would like to thank NSERC for financial assistance through a PGSB grant. We thank Richard Humber and Lynne Sigler for providing us with cultures from the USDA Entomopathogenic Fungus Collection at Cornell University and the University of Alberta Microfungus Collection and Herbarium, respectively.

\section{REFERENCES}

Applied Biosystems (1992). SeqEd. Version 1.0.3. Foster City, CA: Applied Biosystems.

Arora, D. K., Hirsch, P. R. \& Kerry, B. R. (1996). PCR-based molecular discrimination of Verticillium chlamydosporium isolates. Mycol Res 100, 801-809.

Balazy, S., Wisniewski, J. \& Kaczmarek, S. (1987). Some noteworthy fungi occurring on mites. Bull Acad Pol Biol 35, 197-224.

Barasubiye, T., Parent, J.-G., Hamelin, R. C., Laberge, S., Richard, C. \& Dostaler, D. (1995). Discrimination between alfalfa and potato isolates of Verticillium albo-atrum using RAPD markers. Mycol Res 99, 1507-1512.

Bonnen, A. M. \& Hopkins, C. (1997). Fungicide resistance and population variation in Verticillium fungicola, a pathogen of the button mushroom, Agaricus bisporus. Mycol Res 101, 89-96. 
Cabot, E. L. \& Beckenbach, A. T. (1989). Simultaneous editing of multiple nucleic acid and protein sequences with ESEE. Comput Appl Biosci 5, 233-234.

Carder, J. H. \& Barbara, D. J. (1991). Molecular variation and restriction fragment length polymorphisms (RFLPs) with and between six species of Verticillium. Mycol Res 95, 935-942.

Durrands, P. K. \& Cooper, R. M. (1988). Development and analysis of pectic screening media for use in the detection of pectinase mutants. Appl Microbiol Biotechnol 28, 463-467.

Evans, G. \& Gleeson, A. C. (1973). Observations on the origin and nature of Verticillium dabliae colonizing plant roots. Aust J Biol Sci 26, 151-161.

Evans, H. C. \& Samson, R. A. (1986). The genus Verticillium; taxonomic problems in species with invertebrate hosts. In Fundamental and Applied Aspects of Invertebrate Pathology, pp. 186-189. Edited by R. A. Samson, J. A. Vlak \& L. D. Peters. Wageningen: Foundation of the Fourth International Colloquium of Invertebrate Pathology.

Farris, J. S. (1988). Hennig86. Version 1.5. Port Jefferson Station, NY.

Gams, W. (1988). A contribution to the knowledge of nematophagous species of Verticillium. Neth J Plant Pathol 94, 123-148.

Gams, W. \& Van Zaayen, A. (1982). Contribution to the taxonomy and pathogenicity of fungicolous Verticillium species. I. Taxonomy. Neth J Plant Pathol 88, 57-78.

Griffen, A. M., Bainbridge, B. \& Heale, J. B. (1997). Ribosomal, mitochondrial and amplified DNA polymorphisms in Verticillium albo-atrum pathogenic to hops, lucerne and other plants. Mycol Res 101, 1085-1091.

Gunkle, F. A. \& Gassen, H. J. (1989). Proteinase K from Tritorachium album. Eur J Biochem 179, 185-194.

Hankin, C. \& Anagnostakis, S. (1975). The use of solid media for detection of enzyme production by fungi. Mycologia 67, 597-607.

Hillis, D. M. \& Huelsenbeck, J.P. (1992). Signal, noise, and reliability in molecular phylogenetic analyses. J Hered 83, $189-195$.

Hillis, D. M., Allard, M. W. \& Miyamoto, M. M. (1993). Analysis of DNA sequence data: phylogenetic inference. Methods Enzymol 224, $456-487$.

Hu, X., Nazar, R. N. \& Robb, J. (1993). Quantification of Verticillium biomass in wilt disease development. Physiol Mol Plant Pathol 42, 23-26.

Huang, H. C. (1989). Distribution of Verticillium albo-atrum in symptomed and symptomless leaflets of alfalfa. Can J Plant Patbol 11, 235-241.

Joaquim, T. R. \& Rowe, R. C. (1990). Reassessment of vegetative compatibility relationships among strains of Verticillium dabliae using nitrate-nonutilizing mutants. Phytopathology 80, 11601166.

Jun, Y., Bridge, P. D. \& Evans, H. C. (1991). An integrated approach to the taxonomy of the genus Verticillium. J Gen Microbiol 137, 1437-1444.

Leinhos, G. M. E. \& Buchenauer, H. (1992). Hyperparasitism of selected fungi on rust fungi of cereal. J Plant Dis Prot 99, 482-498.

Li, K. N., Rowe, D. I. \& German, T. I. (1994). PCR primers allow intergeneric differentiation of ascomycetes and their application to Verticillium spp. Appl Environ Microbiol 60, 4324-4331.

Maddison, W. P. \& Maddison, D. R. (1992). MacClade: Analysis of Phylogeny and Character Evolution. Sunderland, MA : Sinauer Press.
Moukhamedov, R., Hu, X., Nazar, R. N. \& Robb, J. (1994). Use of polymerase chain reaction-amplified ribosomal intergenic sequences for the diagnosis of Verticillium tricorpus. Phytopathology 84 , 256-259.

Murphy, C. A. \& Walton, J. D. (1996). Three extracellular proteinases from Cochliobolus carbonum: cloning and targetted disruption of ALP1. Mol Plant-Microbe Interact 9, 290-297.

Nazar, R. N., Hu, X., Schmidt, J., Culhan, D. \& Robb, J. (1991). Potential use of PCR-amplified ribosomal intergenic sequences in the detection and differentiation of verticillium wilt pathogens. Mol Plant Pathol 39, 1-11.

Okoli, C. A. N., Carder, J. H. \& Barbara, D. J. (1993). Molecular variation and sub-specific groupings within Verticillium dabliae. Mycol Res 97, 233-239.

Okoli, C. A. N., Carder, J. H. \& Barbara, D. J. (1994). Restriction length polymorphisms (RFLPs) and the relationships of some host-adapted isolates of Verticillium dabliae. Plant Pathol 43, $33-40$.

Robb, J., Moukhamedor, R., Hu., X., Platt, H. \& Nazar, R. (1993). Putative subgroups of Verticillium albo-atrum distinguishable by PCR-based assay. Physiol Mol Plant Pathol 43, 423-496.

Rowe, R. C. (1995). Recent progress in understanding relationships between Verticillium species and subspecific groups. Phytoparasitica 23, 31-38.

Segers, R., Butt, T. M., Kerry, B. R. \& Peberdy, J. F. (1994). The nematophagous fungus Verticillium chlamydosporium produces a chymoelastase-like protease which hydrolyses host nematode proteins in situ. Microbiology 140, 2715-2723.

Siddell, M. E. (1996). Random Cladistics version 4.0. Toronto, ON: Department of Zoology, University of Toronto.

St Leger, R. J. \& Bidochka, M. J. (1996). Insect-fungal interactions. In Invertebrate Immunology, pp. 441-478. Edited by K. Soderhall, G. Vasta \& S. Iwanaga. Fair Haven, NJ: SOS Publications.

St Leger, R. J., Charnley, A. K. \& Cooper, R. M. (1987). Characterization of cuticle-degrading proteases produced by the entomopathogen Metarbizium anisopliae. Arch Biochem Biophys 253, 221-232.

St Leger, R. J., Joshi, L. \& Roberts, D. W. (1997). Adaptation of proteases and carbohydrases of saprophytic, phytopathogenic and entomopathogenic fungi to the requirements of their ecological niches. Microbiology 143, 1983-1992.

Swofford, D. L. (1991). Phylogenetic Analysis using Parsimony (PAUP). Version 3.0. Champaign, IL: Illinois Natural History Survey.

Swofford, D. L. \& Olsen, G. J. (1990). Phylogenetic reconstruction. In Molecular Systematics, pp. 411-501. Edited by D. M. Hillis \& C. Moritz. Sunderland, MA : Sinauer.

Typas, M. A., Griffen, A. M., Bainbridge, B. W. \& Heal, J. B. (1992). Restriction fragment length polymorphisms in mitochondrial and ribosomal RNA gene complexes as an aid to the characterization of species and subspecies populations in the genus Verticillium. FEMS Microbiol Lett 95, 157-162.

White, T. J., Bruns, T. D., Lee, S. B. \& Taylor, J. W. (1990). Analysis of phylogenetic relationships by amplification and direct sequencing of ribosomal DNA genes. In PCR Protocols : a Guide to Methods and Applications, pp. 315-322. Edited by M. A. Innis, D. H. Gelfand, J. J. Sninsky \& T. J. White. New York: Academic Press.

Received 8 September 1998; revised 11 December 1998; accepted 15 December 1998. 